\title{
Torre de Londres e Torre de Hanói: contribuições distintas para avaliação do funcionamento executivo
}

Alana Xavier Batista, Carla Cristina Adda, Eliane Correia Miotto, Mara Cristina Souza de Lúcia, Milberto Scaff

\section{Inserir}

Tabela 1 na página 137, conforme abaixo:

Tabela 1. Principais características dos estudos comparativos do desempenho na TH e TL em pessoas normais.

\begin{tabular}{|c|c|c|c|c|c|}
\hline \multirow{2}{*}{ Tipo de estudo } & \multirow{2}{*}{ Autores } & \multicolumn{3}{|c|}{ Instrumentos utilizados } & \multirow{2}{*}{ Observações } \\
\hline & & Torre de Hanói & Torre de Londres & Outros instrumentos & \\
\hline $\begin{array}{l}\text { Avaliação da } \\
\text { consistência } \\
\text { interna dos testes }\end{array}$ & Humes et al., 1997 & $\begin{array}{l}\text { Problemas em ordem crescente de } \\
\text { dificuldade } \\
\text { Solução com o mínimo de movi- } \\
\text { mentos possíveis }\end{array}$ & $\begin{array}{c}\text { TL (Shallice,1982) } \\
15 \text { problemas com níveis } \\
\text { diferentes de dificuldade até } 5 \\
\text { movimentos. } \\
\text { Solução dos problemas com } \\
\text { número predeterminado de } \\
\text { movimentos. }\end{array}$ & - & - \\
\hline $\begin{array}{l}\text { Aumento da } \\
\text { consistência interna } \\
\text { da torre } \\
\text { de Londres }\end{array}$ & $\begin{array}{l}\text { Schinirman et al., } \\
1998\end{array}$ & $\begin{array}{l}\text { Problemas em ordem crescente de } \\
\text { dificuldade } \\
\text { Solução dos problemas com o } \\
\text { mínimo de movimentos possíveis } \\
\text { Consistência interna alta }\end{array}$ & $\begin{array}{c}\text { TL - Revisada (TL-R) } \\
30 \text { problemas com níveis } \\
\text { diferentes de dificuldade até } 6 \\
\text { movimentos. } \\
\text { Solução dos problemas com } \\
\text { número predeterminado de } \\
\text { movimentos. } \\
\text { Maior consistência interna. }\end{array}$ & - & - \\
\hline \multirow[t]{3}{*}{$\begin{array}{l}\text { Avaliação da } \\
\text { influência de } \\
\text { processos } \\
\text { cognitivos }\end{array}$} & Welsh et al., 1999 & $\begin{array}{l}\text { Problemas em ordem crescente de } \\
\text { dificuldade } \\
\text { Solução dos problemas com o } \\
\text { mínimo de movimentos possíveis. }\end{array}$ & $\begin{array}{c}\text { TL }- \text { Re reduzida } \\
25 \text { problemas com níveis } \\
\text { diferentes de dificuldade até } 6 \\
\text { movimentos. } \\
\text { Solução dos problemas com núme- } \\
\text { ro predeterminado de movimentos }\end{array}$ & $\begin{array}{l}\text { Memória de trabalho } \\
\text { Visual Memory Span } \\
\text { Spatial Working Memory } \\
\text { Controle inibitório } \\
\text { Stroop Test* } \\
\text { Contingence Naming Test** }\end{array}$ & $\begin{array}{l}\text { Escolha dos instrumentos baseada } \\
\text { em seu uso amplo na literatura e } \\
\text { sua validade }\end{array}$ \\
\hline & Bull et al., 2004 & $\begin{array}{l}\text { Problemas em ordem crescente de } \\
\text { dificuldade } \\
\text { Solução dos problemas com o } \\
\text { mínimo de movimentos possíveis } \\
\text { Adaptada para pré-escolares }\end{array}$ & $\begin{array}{l}\text { TL }- \text { NEPSY } \\
20 \text { problemas com níveis } \\
\text { diferentes de dificuldade até } 7 \\
\text { movimentos. } \\
\text { Solução dos problemas com núme- } \\
\text { ro predeterminado de movimentos }\end{array}$ & $\begin{array}{l}\text { Memória de trabalho } \\
\text { Digit Span } \\
\text { Controle Inibitório } \\
\text { Shape School-Inhibition* } \\
\text { Flexibilidade Cognitiva } \\
\text { Shape School-Shifting** }\end{array}$ & $\begin{array}{c}\text { Escolha dos instrumentos baseada } \\
\text { na faixa etária avaliada }\end{array}$ \\
\hline & Zook et al., 2004 & $\begin{array}{l}\text { TH - CATs (Colorado Assessment } \\
\text { Tests) } \\
\text { Problemas de } 3 \text { a } 4 \text { discos de torre } \\
\text { para torre } \\
\text { Solução dos problemas com núme- } \\
\text { ro predeterminado de movimentos }\end{array}$ & $\begin{array}{c}\text { TL - CATs } \\
21 \text { problemas com níveis de } \\
\text { dificuldade até } 6 \text { movimentos } \\
0 \text { número de pinos e bolas variou } \\
\text { de } 3 \text { a } 5 \text { para cada problema } \\
\text { Solução dos problemas com míni- } \\
\text { mo de movimentos possíveis }\end{array}$ & $\begin{array}{c}\text { Memória de trabalho } \\
\text { Visual Span - CATs } \\
\text { Memory Cards - CATs } \\
\text { Controle Inibitório } \\
\text { Stroop Task* } \\
\text { Colorado Card Sort Task (CCST)** } \\
\text { Inteligência fluida } \\
\text { Matrix Reasoning - WAIS-III }\end{array}$ & $\begin{array}{l}\text { Todos os testes, com exceção do } \\
\text { Matrix Reasoning, foram aplicados } \\
\text { em versão computadorizada. }\end{array}$ \\
\hline \multirow[t]{2}{*}{$\begin{array}{l}\text { Mudança nos } \\
\text { procedimentos de } \\
\text { administração e } \\
\text { pontuação }\end{array}$} & Welsh et al., 2000 & $\begin{array}{c}\text { TH - I } \\
12 \text { problemas em ordem crescente } \\
\text { de dificuldade } \\
\text { Administração semelhante à TL-R } \\
\text { Não foi modificada a estrutura } \\
\text { do teste } \\
\text { Baixa consistência interna }\end{array}$ & $\begin{array}{c}\text { TL }-\mathrm{R} \\
30 \text { problemas com níveis } \\
\text { diferentes de dificuldade até } 6 \\
\text { movimentos } \\
\text { Solução dos problemas com núme- } \\
\text { ro predeterminado de movimentos }\end{array}$ & - & - \\
\hline & $\begin{array}{l}\text { Welsh, Huizinga, } \\
2001\end{array}$ & $\begin{array}{c}\text { TH-Revisada, } \\
22 \text { problemas em ordem ascen- } \\
\text { dente de dificuldade } \\
\text { Administração semelhante à TL-R } \\
\text { Não foi modificada a estrutura } \\
\text { do teste } \\
\text { Maior consistência interna }\end{array}$ & $\begin{array}{c}\text { TL }-\mathrm{R} \\
30 \text { problemas com níveis } \\
\text { diferentes de dificuldade até } 6 \\
\text { movimentos } \\
\text { Solução dos problemas com núme- } \\
\text { ro predeterminado de movimentos }\end{array}$ & - & - \\
\hline
\end{tabular}


J Bras Psiquiatr. 2008;57(1):2-8.

\section{Onde se lê:}

Perceptions of the symptoms of depression between members of three ethnic communities in Santa Catarina: Azoreans, Italians and Germans

\section{Leia-se}

Perception and expression of the symptoms of depression in three ethnic groups in Santa Catarina, Brazil: Italians, Germans and Azorean 